\title{
GAS CHROMATOGRAPHY COUPLED WITH MASS SPECTROMETRY DETECTION FOR THE VOLATILE PROFILING OF VITIS VINIFERA CV. CARMÉNÈRE WINES
}

\author{
ANA MARÍA DOMÍNGUEZ ${ }^{1 *}$ AND EDUARDO AGOSIN ${ }^{1,2}$
}

${ }^{I}$ Centro de Aromas, DICTUC SA, and ${ }^{2}$ Department of Chemical and Bioprocess Engineering, School of Engineering, Pontificia Universidad Catolica de Chile,

Av. Vicuña Mackenna 4860, Macul, Santiago, CHILE.

(Received: April 7, 2010 - Accepted: June 4, 2010)

\begin{abstract}
The volatile metabolome of Vitis vinifera C.V. Carménère wines, a unique Chilean winegrape variety, was characterized in this work. After solvent extraction with dichloromethane (LLE) or head space solid phase microextraction (HS-SPME), the resulting volatile compounds were analyzed by gas chromatographymass spectrometry (GC-MS). Specific methods were carried out too for the determination of methoxypyrazines and thiols. Almost 150 compounds corresponding to aliphatic and aromatic alcohols, organic acids, acetate and ethyl esters, lactones, terpenes, norisoprenoids, pyrazines, thiols and phenolic compounds were found in these wines. Both extraction techniques were complementary; HS-SPME allowed to identify several important compounds that were not detected by liquid-liquid solvent extraction, in particular b-damascenone, nerolidol, citronellol, linalool, ethyl 2-methyl-butyrate and geranyl acetone. Several varietal volatile compounds with significant odorant properties were also identified: 3-mercaptohexyl acetate (3MHA), 3-mercaptohexan-1-ol (3MH), benzenemethanethiol (BM), 2-furanmethanethiol (2FM); and 2-isobutyl-3-methoxypyrazine (IBMP) while 2-isopropyl-3-methoxypyrazine (IPMP) and 4-mercapto-4-methylpentan2-one (4MMP) were not detected. Twenty two of these compounds, including b-damascenone, several thiols, ethyl octanoate, 2-phenylethanol, and 2-isobutyl-3methoxypyrazine, showed significant odor activities values (OAV), and were clearly related with the cooked fruits, berries-like and herbaceous notes characteristic of Carménère wines. Olfactometric techniques are underway to validate the sensory impact of these compounds.
\end{abstract}

\section{INTRODUCTION}

Wine quality and identity are the result of several interacting factors, particularly terroir and grape variety, but also viticultural and winemaking practices. Wine aroma is a key component of the former. It is composed by several hundred of volatile compounds that belong to different chemical families, arising from the grape metabolism, the yeast fermentation and the aging process. Several studies have already recognized the close relationship between the varietal, differential character of a wine and the grapes from which it is produced. Many of these compounds - terpenes, sesquiterpenes, norisoprenoids, benzene derivatives, aromatic alcohols and C6 alcohols - are able to break the common "vinous matrix" present in any wine, to express the unique features of the variety in the wine ${ }^{1-4}$.

Some important compounds of the wine aroma include: C6-compounds like 1-hexanol, (E)-3-hexenol and (Z)-3-hexenol, responsible for some green notes, normally released during prefermentative operations ${ }^{5,6}$; higher alcohols, fatty acids and esters produced during yeast fermentation 7,8 ; key aromatic varietal compounds such as monoterpenes, norisoprenoids and thiols mostly released during fermentation and aging, from their conjugated forms by chemical or enzymatic hydrolysis ${ }^{9-11}$; and unique varietal compounds, like rotundone in Shiraz ${ }^{12}$, furaneol in rosé wines ${ }^{13}$, cis-rose oxide in Gewürztraminer, 4-methyl-4-mercaptopentanone in Sauvignon Blanc ${ }^{14}$ or methoxypyrazines in Sauvignon and Carménère varieties 15,16 .

These volatile components belong to many chemical families and show specific features, such as different polarity, solubility, volatility, stability, oxidation and degradation, among others. Thus, several extraction techniques have been employed to ensure full characterization of the volatile profile of grapes and wines, like solid-phase extraction (SPE) ${ }^{17-19}$; stir bar sorptive extraction (SBSE) ${ }^{20,21}$, solvent-assisted flavor evaporation (SAFE) 22, 23; dynamic headspace sampling ${ }^{24,25}$; and liquid extraction with organic solvents (LLE) ${ }^{26-28}$. Although the latter is time consuming and could involve contamination with solvents, losses during the final concentration steps as well as artifact generation, it is still the most widely used extractive technique. A more recent, increasingly popular technique is solid-phase microextraction (SPME), which is based on the partitioning of analytes between the sample matrix and the extracting phase coating. The latter can be used for analyte concentration either by submersion in the liquid phase or by exposure to the gaseous phase in the headspace (HS-SPME). The sorbed analytes are thermally desorbed in a conventional GC injection port. This is a simple, fast, inexpensive, sensitive and solvent-free methodology $29-32$.

Vitis vinifera cv. Carménère, is a red grape variety originating from Bordeaux, France, that was believed to be extinguished after the phylloxera plague that ravaged the french vineyard in the mid 19th century. However, in
1994, the variety was re-discovered in Chile, mostly mixed with Merlot vines. Carménère is currently the Chilean flagship variety with more than 7,000 hectares planted in most of the valleys of the country. This variety has adapted particularly well to the Chilean climate, soil and geographical conditions. Quantitative descriptive analyses of Carménère wines showed two major groups of descriptors associated with green, herbaceous notes on one side; and fruity, spicy, berry like notes on the other ${ }^{33}$. Belancic and Agosin ${ }^{16}$ recently demonstrated the importance of methoxypyrazines in relation with the strong vegetative aroma.

In this work, was studied the volatile chemical profiling from two regions of Chile monovarietal Carménère wines. The compounds present in high concentrations (major compounds) were extracted using different extraction methods: LLE and HS-SPME. Also, specific extraction techniques were employed for the isolation and quantitation of volatile compounds present at trace levels (minor compounds), i.e. pyrazines and thiols. Identification of several high impact odorants of Carménère wines and their correlation with known sensory descriptors of the variety was also attempted.

\section{Experimental part}

\section{Materials}

The two Carménère wines employed in this study were kindly donated, between the years 2007 and 2009, by Perez Cruz and Casa Silva wineries, situated in Maipo and Colchagua valleys, respectively. They were stored in the bottles at $15^{\circ} \mathrm{C}$ until their analysis. These, 2007, 2008 and 2009 wines were selected by the winemakers for their tipicity. The six Carménère wines samples were analyzed individually, in triplicate. Results shown in Table 1 correspond to the average data from all the Carménère wines analyzed, because their volatile profile was quite similar.

Dichloromethane, ethyl acetate, sodium p-hydroxymercurybenzoate, cysteine monohydrate hydrochloride, anhydrous sodium sulfate, 4-nonanol (internal standard) and DOWEX 1 resin were purchased from Merck (Darmstadt, Germany). Water was purified with a MilliQ system from Millipore (Bedford, MA). Nitrogen and helium gases were supplied by Indura (Santiago Chile). Deuterated 2-isobutyl-3-methoxypyrazine (d,-IBMP) used as internal standard, 2-isobutyl-3-methoxypyrazine and 2-isopropyl-3-methoxypyrazine were purchased by Sigma-Aldrich. Chemos (Germany) provided the thiols: heptanethiol (internal standard), 4-mercapto-4-methylpentan-2one, 3-mercaptohexan-1-ol, 3-mercaptohexyl acetate, 2-furanmethanethiol and benzenemethanethiol. Three SPME fibers of different polarity from Supelco, Sigma-Aldrich: $100 \mu \mathrm{m}$ Polydimethylsiloxane (PDMS), 50/30 $\mu \mathrm{m}$ Divinylbenzene/Carboxen/Polydimethylsiloxane (DVB/CAR/PDMS) and $85 \mu \mathrm{m}$ Polyacrylate (PA), were used to provide complementary information about volatile profile of Carménère wines. 


\section{Liquid Liquid Extraction (LLE)}

$100 \mathrm{ml}$ of wine, spiked with $354 \mu \mathrm{g}$ of 4-nonanol as internal standard was extracted twice with $25 \mathrm{ml}$ of dichloromethane at $4^{\circ} \mathrm{C}$ under nitrogen atmosphere. The sample was stirred for $30 \mathrm{~min}$ and then centrifuged at $5^{\circ} \mathrm{C}$ and $5000 \mathrm{rpm}$. The organic phases were combined and concentrated to $1 \mathrm{~mL}$ in a Vigreux column; then, the extract was gently reduced to $350 \mathrm{uL}$ with nitrogen gas. $2 \mathrm{uL}$ of this concentrated wine organic extract was employed for GC/MS analysis. All the analyses were done in triplicate.

\section{HS-SPME extraction}

$20 \mathrm{~mL}$ of wine at a 1:1 dilution with milliQ water were placed in a 40 $\mathrm{mL}$ volume vial; after the addition of the internal standard and $1 \mathrm{~g}$ of $\mathrm{NaCl}$ the vial was sealed with a Teflon septum and equilibrated at $40^{\circ} \mathrm{C}$ for 5 min with agitation. The fiber was then introduced and exposed to the bottle head space during 1 hour, keeping the agitation and vial temperature. After this period, the fibre was retracted and the adsorbed volatile compounds were thermally desorbed for $20 \mathrm{~min}$ at the injection port of the GC/MS equipment.

\section{Minor compounds}

Pyrazines extraction and quantitation was carried out in triplicate using the method reported by Belancic ${ }^{16}$.

Thiols were isolated and extracted using DOWEX anionic exchange resins as reported by Tominaga ${ }^{34}$.

\section{GC/MS analysis}

A GC/MS Hewlett Packard 6890 gas chromatograph (GC) coupled to a HP 5973 mass selective detector (MSD) was used for the analyses. The analytes were separated on a DB Wax capillary column $(60 \mathrm{~m} \times 0,25 \mathrm{~mm} \times 0,25 \mu \mathrm{m})$, applying the following temperature program: $40^{\circ} \mathrm{C}$ for $5 \mathrm{~min}$; from $40^{\circ} \mathrm{C}$ to $240^{\circ} \mathrm{C}$, temperature was raised at $3 \% \mathrm{~min}$ and then holding for $10 \mathrm{~min}$. The transfer line was settled at $250^{\circ} \mathrm{C}$ and mass detector conditions were: scan mode with electronic impact (EI) at $70 \mathrm{eV}$ and source temperature of $150^{\circ} \mathrm{C}$. Ultrapurified helium was used as the carrier gas with a nominal flow rate of 1.5 $\mathrm{ml} / \mathrm{min}$. The injections were carried out in splitless mode, setting the injector temperature for LLE at $180^{\circ} \mathrm{C}$ and for SPME at $250^{\circ} \mathrm{C}$. Identification of the volatile components was achieved by comparing the mass spectra with the data system library (NIST/EPA/NIH). All compounds were quantified as 4-nonanol equivalents. All the data showed a coefficient of variation lower than $15 \%$.

\section{RESULTS AND DISCUSSION}

\section{(LLE)}

Analysis of Carménère wines volatiles extracted with organic solvent

The GC/MS analysis of the Carménère Chilean wines revealed the complex chemical profile of this kind of matrix (Table 1) with the presence of several compounds belonging to different chemical families, like alcohols, esters, carbonyl compounds, acids, furfural and shikimic derivatives, among others. As usual for most alcoholic beverages ${ }^{8,19,35}$, the most quantitatively significant volatile compounds in these wines corresponded to yeast-derived fermentative alcohols and esters. Alcohols represented 52\% of the total volatile composition, followed by the esters $(32 \%)$. The former group - 21 volatile compounds - is mainly composed by isoamyl alcohol (fusel alcohol note) and 2-phenylethanol (roses, pollen, flowery notes). Esters represented the highest number of volatiles identified (34 compounds). These compounds are mainly responsible for sweet, fruity and floral sensory notes in wines. Monoethyl succinate, ethyl lactate and diethyl succinate showed the highest concentrations. Ethyl 3-hydroxy-butyrate was present at a concentration of 206 $\mu \mathrm{g} \mathrm{L}{ }^{-1}$, in average. The latter compound has been reported earlier as a possible contributor of strawberry and burnt marshmallow notes in Pinot Noir wines, as pointed out in Ugliano et al. ${ }^{36}$.

The C6 derivative compounds, 1-hexanol, (Z)-3-hexenol, (E)-3-hexenol, and (E)-2-hexenol represent, in average, only $0,5 \%$ of the total volatile composition. These volatiles are formed via lipoxygenase activity of the grape during pre-fermentative steps including harvesting, crushing, pressing and grape maceration ${ }^{6,37}$. Both Carménère wines showed a similar proportion of these compounds, with major quantity of 1-hexanol followed by E-3-hexenol.

Fermentative fatty acids are responsible for sour, mild, rancid and cheesy notes in wines. They were represented as $7 \%$ of the total wine volatile composition of Carménère wines, with acetic, octanoic and hexanoic acids being the major quantitative contributors.

Carbonyl volatile compounds, equivalent to $1 \%$ of the total volatile concentration, are formed as byproducts of microbial fermentation and chemical oxidation or from oak-barrels during winemaking and aging
38. Acetoine and 2, 3-butanedione (diacetyl) were the major quantitative contributors in both wines. Acetoine is formed by the reduction of diacetyl; the latter is an intermediate in the decarboxylative reduction of pyruvic acid to 2 , 3-butanediol. These volatile compounds give to wines buttery or butterscotch, nutty, and also sweet, caramel attributes ${ }^{39,40}$.

The origin of sulfur compounds in wines involves physical and microbial reduction reactions ${ }^{41}$. In Carménère wines, these compounds reached $0,4 \%$ of the total volatile composition. Sulfur compounds are mostly responsible for the production of unpleasant or reduced flavours in wines like cabbage, cooked vegetable, onion and garlic. 3-methylthio-1-propanol (methionol) was the dominant sulfur volatile compound in the wines, reaching a concentration of $396 \mu \mathrm{g} \mathrm{L}^{-1}$. This methionine derived compound has been reported to vary largely, according to the grape variety; if present in sufficiently high concentration, it gives a potato-, meat-like note to wines. It has been reported in wines at concentrations between 145 and $2000 \mu \mathrm{g} \mathrm{L}{ }^{-136,42,43}$.

Volatile compounds such as lactones, volatile phenols, shikimic acid derivatives and furfural derivatives migrate from oak wood to wine during maceration with oak chips or aging, playing an important role in wine quality 44-46. In Carménère wines, this group of substances represents $6,2 \%$, of the total volatile composition, with g-butyrolactone, furfural and 4-carbethoxy-gbutyrolactone as the major contributors.

Terpenes and norisoprenoids are varietal components which play an important role in the flavour of wines. Their content is mostly related with the grape variety and viticultural factors (terroir, climate, water retention capacity, sun exposition, irrigation treatment, etc.). Terpenes could be found in grapes as sugar-conjugated, odourless precursors or as free volatiles. The most common representatives of this family are linalool, geraniol, nerol, linalool oxides, a-terpineol and nerol oxide. Norisoprenoids are formed by direct, oxidative degradation of carotenoids, such as b-carotene or lycopene, and can be stored as glycoconjugates, too. The terpenes and norisoprenoids in their odorant form can be further released from their glycoside precursors through acid or enzymatic hydrolysis during fermentation and aging. Norisoprenoids have very low olfactory perception thresholds and so, they have a high sensorial impact on wine aroma ${ }^{47,48}$. In the solvent-extracted Carménère wines, only two norisoprenoids were found, i.e. iridomyrmecin - in low concentration and only for Colchagua valley - and 3-oxo-a-ionol which contributes with honey and tobacco notes. An increase in the concentration of these compounds, as well as the release of other norisoprenoids, such as a- and b- ionol and their derivatives, 3-hydroxy-damascone, vitispiranes, vomifoliol, etc. during Carménère aging was recently demonstrated ${ }^{49,50}$.

Table 1. Average concentration of free volatile compounds found in young Carménère wines using LLE and HS-SPME with PDMS, DVB/CAR/ PDMS and PA fibers.

\begin{tabular}{|l|c|c|c|c|}
\hline & LLE & \multicolumn{3}{|c|}{ HS-SPME } \\
\hline Compound & $\left(\mu \mathbf{~ L ~}^{-1}\right)$ & \multicolumn{3}{|c|}{$\left(\mu \mathbf{g ~ L}^{-1}\right)$} \\
\hline & & \multirow{2}{*}{ PDMS } & $\begin{array}{c}\text { DVB/ } \\
\text { CAR/ } \\
\text { PDMS }\end{array}$ & PA \\
\hline Carbonyl compounds & & & & \\
\hline acethaldehyde & & 6 & & \\
\hline 2,3-butanedione & 722 & 28 & 9 & 13 \\
\hline 2,3-pentanedione & 109 & 3 & 2 & \\
\hline acetoin & 1096 & 4 & & \\
\hline 3-methyl-3-buten-2-one & 10 & & & \\
\hline 4-nonanone & & 12 & 19 & \\
\hline 3-ethyl-4-heptanone & 9 & & 28 & \\
\hline 2-hydroxy-pentan-3-one & 72 & & & \\
\hline 4-hydroxy-4-methyl-2-pentanone & 35 & & & \\
\hline benzaldehyde & 8 & & & \\
\hline 2-octanone & 9 & & & \\
\hline 1-hydroxy-2-propanone & $28^{\mathrm{a}}$ & & & \\
\hline 3-hydroxy-4-phenyl-2-butanone & $41^{\mathrm{a}}$ & & & \\
\hline Total average & $\mathbf{2 1 3 9}$ & $\mathbf{5 6}$ & $\mathbf{5 9}$ & $\mathbf{1 3}$ \\
\hline & & & & \\
\hline
\end{tabular}


DVB/CAR/PDMS

\begin{tabular}{|c|c|c|c|c|c|c|c|c|c|}
\hline & LLE & \multicolumn{3}{|c|}{ HS-SPME } & b-damascenone & & 30 & 22 & \\
\hline Compound & $\left(\mu \mathrm{g} \mathrm{L}^{-1}\right)$ & \multicolumn{3}{|c|}{$\left(\mu \mathrm{g} \mathrm{L}^{-1}\right)$} & geranyl acetone & & 11 & 4 & \\
\hline & & \multirow{2}{*}{ PDMS } & DVB/ & \multirow[b]{2}{*}{ PA } & nerolidol & & 34 & 8 & 24 \\
\hline & & & $\begin{array}{l}\text { CAR/ } \\
\text { PDMS }\end{array}$ & & Total average & 1074 & 93 & 55 & 24 \\
\hline Alcohols Cont. & & & & & & LLE & \multicolumn{3}{|c|}{ HS-SPME } \\
\hline n-propanol & 313 & 19 & 13 & 35 & Compound & $\left(\mu \mathrm{g} \mathrm{L}^{-1}\right)$ & \multicolumn{3}{|c|}{$\left(\mu \mathrm{g} \mathrm{L}^{-1}\right)$} \\
\hline isobutanol & 2768 & 44 & 80 & 87 & & & \multirow{3}{*}{ PDMS } & \multirow{3}{*}{$\begin{array}{l}\text { DVB/ } \\
\text { CAR/ } \\
\text { PDMS }\end{array}$} & \multirow{3}{*}{ PA } \\
\hline 1-butanol & 264 & & & & & & & & \\
\hline isoamyl alcohol & 45460 & \multirow{3}{*}{1634} & \multirow[t]{3}{*}{1310} & \multirow[t]{3}{*}{2235} & & & & & \\
\hline 3-methyl-3-buten-1-ol $\quad+$ & \multirow{2}{*}{43} & & & & Esters Cont. & & & & \\
\hline 1-pentanol & & & & & methyl acetate & & & 5 & \\
\hline 4-methyl-1-pentanol & 40 & & & & ethyl acetate & & 720 & 707 & 623 \\
\hline 4-heptanol & 10 & 4 & 4 & & ethyl propanoate & 73 & & & \\
\hline 2-heptanol & 5 & & & & ethyl isobutyrate & 18 & 12 & 4 & \\
\hline 1-Heptanol & $\begin{array}{l}58 \\
81\end{array}$ & & & & propyl acetate & 27 & 4 & 3 & \\
\hline 3-methyl-1-pentanol & $\frac{81}{158}$ & & & & isobutyl acetate & 43 & 7 & 6 & \\
\hline 3-ethoxy-1-propanol & $\frac{158}{540 ?}$ & & & & ethyl butyrate & 120 & 46 & 31 & 12 \\
\hline 2,3-butanediol & $\begin{array}{l}5492 \\
1165\end{array}$ & 28 & & 23 & ethyl -2-methyl-butyrate & & 6 & 4 & \\
\hline $\begin{array}{l}\text { 1,3-butanediol } \\
\text { 2-(2-butoxy-ethoxy ethanol) }\end{array}$ & 36 & & & & ethyl isovalerate & 9 & 8 & 6 & \\
\hline benzyl alcohol & 191 & & & & butyl acetate & $9^{\mathrm{b}}$ & & & \\
\hline 2-phenylethanol & 19937 & 122 & 235 & 627 & isoamyl acetate & 908 & 742 & 579 & 287 \\
\hline 3-octanol & 10 & 17 & 20 & 13 & ethyl hexanoate & 267 & 662 & 524 & 206 \\
\hline 2,6-dimethyl-4-heptanol & $164^{\mathrm{b}}$ & & & & hexyl acetate & 46 & 31 & 27 & \\
\hline 3-ethyl-4-heptanol & & 12 & 13 & & ethyl E-2-hexenoate & & 8 & & \\
\hline octanol & 25 & 7 & 9 & 10 & ethyl lactate & 12533 & 38 & 38 & 54 \\
\hline 6-undecanol & & 129 & 112 & 90 & ethyl-2-hydroxy butyrate & 5 & & & \\
\hline 1-decanol & & & 7 & & methyl octanoate & & 8 & 8 & \\
\hline 1-dodecanol & & 25 & 2 & & ethyl octanoate & 499 & 4144 & 3456 & 1790 \\
\hline 3-methyl-3-buten-2-ol & $200^{\mathrm{a}}$ & & & & ethyl-3-hydroxybutyrate & 206 & & & \\
\hline 2-methyl-3-buten-2-ol & $32^{\mathrm{a}}$ & & & & isoamyl hexanoate & & & 15 & \\
\hline Total average & 76452 & 312 & 398 & 740 & 2,3-butanediol monoacetate & 171 & & & \\
\hline & & & & & ethyl nonanoate & & 27 & 22 & 10 \\
\hline C6 Compounds & & & & & methyl decanoate & & & 4 & \\
\hline 1-hexanol & 615 & 50 & 52 & 64 & ethyl decanoate & $129^{\mathrm{b}}$ & 1688 & 1018 & 989 \\
\hline E-3-hexen-1-ol & 51 & & & & isoamyl octanoate & & 51 & 32 & 27 \\
\hline Z-3-hexen-1-ol & 20 & & & & diethyl succinate & 7114 & 285 & 317 & 339 \\
\hline Z-2-hexen-1-ol & 7 & & & & 1,3-propanediol monoacetate & 313 & & & \\
\hline Total average & 693 & 50 & 52 & 64 & ethyl 9-decanoate & & 515 & 274 & 305 \\
\hline & & & & & 2-phenyl ethyl acetate & & 46 & 42 & 51 \\
\hline Acids & & & & & diethyl-2-hydroxypentanedioate & $337^{\mathrm{b}}$ & & & \\
\hline acetic acid & 4990 & 66 & 41 & & ethyl-2-hydroxy-3-phenyl & $358^{\mathrm{b}}$ & & & \\
\hline propanoic acid & 29 & & & & propanoate & $358^{\circ}$ & & & \\
\hline isobutyric acid & 312 & & & & monoethyl succinate & 21337 & & & \\
\hline butyric acid & 214 & & & & ethyl 4-hydroxy-glutarate & 587 & & & \\
\hline valeric acid & 1027 & & & & isopropyl dodecanoate & & 11 & & \\
\hline hexanoic acid & 1076 & 10 & 24 & & ethyl pyroglutamate & 77 & & & \\
\hline 2-hexenoic acid (isom.) & 14 & & & & ethyl dodecanoate & & 121 & 23 & 79 \\
\hline heptanoic acid & 10 & & & & isoamyl decanoate & & 6 & & \\
\hline octanoic acid & 1656 & 157 & 147 & & monoisoamyl succinate & $646^{\mathrm{b}}$ & & & \\
\hline decanoic acid & 354 & 95 & 26 & & isoamyl lactate & $87^{\mathrm{a}}$ & & & \\
\hline hexadecanoic acid & 102 & & & & hexyl butanoate & & 8 & & \\
\hline phenyl acetic acid & 104 & & & & ethyl phenyl lactate & 352 & & & \\
\hline Total average & 9888 & 329 & 238 & & ethyl 3-hydroxy-3-methyl butyrate & $11^{\mathrm{a}}$ & & & \\
\hline & & & & & ethyl 2-hydroxy-3-methyl-butyrate & $60^{\mathrm{a}}$ & & & \\
\hline Terpenes and norisoprenoids & & & & & ethyl pyruvate & $22^{\mathrm{a}}$ & & & \\
\hline 3-oxo-a-ionol & 25 & & & & ethyl 4-acetyloxy-butyrate & $1020^{\mathrm{a}}$ & & & \\
\hline iridomyrmecin & $6^{\mathrm{b}}$ & & & & ethyl citrate & $80^{\mathrm{a}}$ & & & \\
\hline tyrosol & 1043 & & & & 4-ethyl-phenyl acetate & $14^{\mathrm{a}}$ & & & \\
\hline linalool & & 6 & 7 & & ethyl 3-hydroxy-hexanoate & $264^{\mathrm{a}}$ & & & \\
\hline b-citroneroll & & 12 & 14 & & ethyl n-propyl succinate & $49^{\mathrm{a}}$ & & & \\
\hline
\end{tabular}




\begin{tabular}{|c|c|c|c|c|}
\hline ethyl isoamyl succinate & & 87 & 45 & 53 \\
\hline ethyl p-hydroxycinnamate & & & 841 & \\
\hline ethyl pentadecanoate & & 10 & & \\
\hline ethyl hexadecanoate & & 17 & & 17 \\
\hline Total average & 47791 & 9308 & 8030 & 4843 \\
\hline \multicolumn{5}{|l|}{ Sulfur compounds } \\
\hline $\begin{array}{l}2 \text { - meth y } 1-\mathrm{dih} \text { y dro- }-3(2 \mathrm{H})- \\
\text { thiophenone }+2 \text {-methylthioethanol }\end{array}$ & 46 & & & \\
\hline 3-methylthio-1-propanol & 396 & & & \\
\hline dimethylsulphone & 25 & & 6 & \\
\hline 3-methylthiopropanoic acid & 43 & & & \\
\hline methyl thioacetate & 5 & & & \\
\hline 3-ethylthio-1-propanol & $65^{\mathrm{a}}$ & & & \\
\hline Total average & 580 & & 6 & \\
\hline \multicolumn{5}{|l|}{ Nitrogen compounds } \\
\hline N-3-methylbutyl acetamide & 136 & & & \\
\hline 2-phenylethyl acetamide & 72 & & & \\
\hline $\mathrm{N}$-acetyl glycine & $79^{\mathrm{a}}$ & & & \\
\hline N,N-diethylbencylamine & $29^{\mathrm{a}}$ & & & \\
\hline ethyl $\mathrm{N}$-acetyl methionine & $15^{\mathrm{a}}$ & & & \\
\hline Total average & 331 & & & \\
\hline \multicolumn{5}{|l|}{ Furfural and furanic derivatives } \\
\hline furfural & 1623 & 26 & 231 & 84 \\
\hline 5-hydroxy-methylfurfural & 290 & & & \\
\hline 2-acetylfuran & 63 & & & \\
\hline 5-methyl-furfural & $305^{\mathrm{a}}$ & 18 & 25 & 32 \\
\hline furfuryl alcohol & 194 & & & \\
\hline isobenzofuranone & 42 & & & \\
\hline ethyl-2-furoate & $5^{\mathrm{b}}$ & & & \\
\hline 4,6-dimethyl-2H-pyran-2-one & 5 & & & \\
\hline 2-hydroxy-4-pyranone & 119 & & & \\
\hline Total average & 3772 & 44 & 256 & 116 \\
\hline \multicolumn{5}{|l|}{ Lactones } \\
\hline g-butyrolactone & 2334 & & & \\
\hline 4-ethoxy-g-butyrolactone & 15 & & & \\
\hline whiskey lactone $(\mathrm{Z})$ & 181 & & 10 & \\
\hline \multirow[t]{2}{*}{ 4-carbethoxy-g-butyrolactone } & 481 & & & \\
\hline & LLE & \multicolumn{3}{|c|}{ HS-SPME } \\
\hline \multirow[t]{2}{*}{ Compound } & $\left(\mu \mathrm{g} \mathrm{L}^{-1}\right)$ & \multicolumn{3}{|c|}{$\left(\mu \mathrm{g} \mathrm{L} \mathrm{L}^{-1}\right)$} \\
\hline & PDMS & & & $\mathrm{PA}$ \\
\hline \multicolumn{5}{|l|}{ Lactones Cont. } \\
\hline g-crotonolactone & $16^{\mathrm{a}}$ & & & \\
\hline whiskey lactone (E) & $60^{\mathrm{a}}$ & & 12 & \\
\hline d-octalactone & $11^{\mathrm{a}}$ & & & \\
\hline mevalonic lactone & $62^{\mathrm{a}}$ & & & \\
\hline g-decanelactone & $31^{\mathrm{a}}$ & & & \\
\hline g-5-hydroxy-hexalactone & $210^{\mathrm{a}}$ & & & \\
\hline Total average & 3462 & & 22 & \\
\hline \multicolumn{5}{|l|}{ Volatile phenols } \\
\hline siringaldehyde & $293^{b}$ & & & \\
\hline ethyl syringoate & 106 & & & \\
\hline syringone acetate & $123^{\mathrm{b}}$ & & & \\
\hline 2-methoxyphenol & 21 & & & \\
\hline
\end{tabular}

\begin{tabular}{|l|c|l|l|l|}
\hline 4-vinylguaiacol & 13 & & & \\
\hline 2,6-dimethoxyphenol & 39 & & & \\
\hline 4-allyl-2,6-dimethoxyphenol & $29^{\mathrm{b}}$ & & & \\
\hline guaiacyl ethanol & 73 & & & \\
\hline guaiacyl propanol & 55 & & & \\
\hline $3,4,5$-trimethoxyphenol & 77 & & & \\
\hline 4-methyl guaiacol & $14^{\mathrm{b}}$ & & & \\
\hline guaiacyl ketone & $15^{\mathrm{b}}$ & & & \\
\hline ethyl guaiacyl propanoate & 9 & & & \\
\hline 4-methoxyacetophenone & $320^{\mathrm{a}}$ & & & \\
\hline phenylethyl benzoate & $111^{\mathrm{a}}$ & & & \\
\hline ethyl 4-hydroxy-benzoate & $75^{\mathrm{a}}$ & & & \\
\hline guaiacol & $11^{\mathrm{a}}$ & & & \\
\hline Total average & $\mathbf{1 3 8 4}$ & & & \\
\hline & & & & \\
\hline Shikimic acid derivatives & & & & \\
\hline vanillin & 118 & & & \\
\hline ethyl vanillate & 83 & & & \\
\hline acetovanillone & 62 & & & \\
\hline propiovanillone & 23 & & & \\
\hline vanillyl methyl ketone & 57 & & & \\
\hline methyl vanillate & $2^{\mathrm{a}}$ & & & \\
\hline Total average & $\mathbf{3 4 4}$ & & & \\
\hline & & & & \\
\hline Others & & & & \\
\hline $\begin{array}{l}\text { E-4-hydroxymethyl-2-methyl-1,3- } \\
\text { dioxolane }\end{array}$ & 41 & & & \\
\hline 4CALA precursor & $\mathbf{9 6}$ & & & \\
\hline Total average & & & & \\
\hline & & & & \\
\hline
\end{tabular}

${ }^{(a)}$ compound only detected for Maipo valley wines; ${ }^{(b)}$ compound only detected for Colchagua valley wines

Analysis of Carménère wines by Head Space Solid Phase MicroExtraction (HS-SPME)

More than 60 volatile compounds could be extracted with HS-SPME technique (Table 1). Because a single fiber cannot extract all the volatiles and their different extraction selectivity, three types of fibers, coated with polymers with increasing polarity, were employed for this purpose: polydimethylsiloxane (PDMS, apolar), divinylbenzene/carboxen/polydimethylsiloxane (DVB/CAR/ PDMS, medium polar) and polyacrylate (PA, polar). The compounds were thermally desorbed and further identified by GC/MS.

With this extraction technique also the main groups of chemical compounds found were esters and alcohols, although in different proportions according to the polarity of the fiber used. Thus, for the PDMS and DVB/CAR/PDMS fiber $78 \%$ and $76 \%$ of esters, respectively, and $17 \%$ of alcohols were extracted. On the other hand, the PA fiber was slightly more selective to alcohols with $38 \%$ of alcohols and $59 \%$ of esters.

Interestingly, some volatiles that could not be detected by LLE were revealed by HS-SPME. The apolar and the mixed polymer coating fibers were able to extract three monoterpenes: linalool, citronellol and geranyl acetone; a sesquiterpene, nerolidol; and a norisoprenoid, b-damascenone. The latter was a particularly interesting compound, because it has been described as an important odorant in red wines with notes of baked apples, marmalade and honey ${ }^{51,52}$.

The PA fiber was more selective to alcohols like isoamyl alcohol and 2-phenyl ethanol. However, DVB/CAR/PDMS fiber extracted methionol (3-methylthio-1-propanol), whiskey lactones (coconut) and ethyl p-hydroxycinnamate (flowery); and the PDMS fiber allowed to extract a higher number of carbonylic compounds. Canuti et al ${ }^{31}$ recently reported that the use of PDMS fiber resulted in greater extraction of norisoprenoids (e.g., damascenone) and terpenes (e.g., linalool), as well as alcohols and the more polar aldehydes, in agreement with our results.

\section{Minor varietal compounds}

Some minor varietal compounds, in particular methoxypyrazines and 
thiols, were also detected. Although these compounds were present at very low concentration, their low odor perception threshold, at the ppt level, generally makes them responsible for a significant impact in the total aroma of wines and other food matrices. 2-isobutyl-3-methoxypyrazine (green bell pepper notes), was identified in the wines at an average concentration of 3,6 $\mathrm{ng} \mathrm{L}^{-1}$. It is worthy to mention that the IBMP concentration in the Carménère wines studied here was much lower than the ones reported by Belancic and Agosin ${ }^{16}$, for 2003 Carménère wines, suggesting that, currently, a better management of this herbaceous character is conducted. 2-isopropyl-3-methoxypyrazine was not detected.

Four thiols were detected and quantitated, too (Table 2). These compounds give to wines, fruits and other diverse sensory notes and some, like 4-mercapto4-methylpentan-2-one or 3-mercaptohexan-1-ol for example, have been classified as high impact odorant compounds in white wines like Sauvignon Blanc ${ }^{53}$. Although 4MMP was detected in Carménère wines, its concentration was very low and it could not be quantitated. 2-furanmethanethiol has been reported for wines aged in oak barrels and in champagne, contributing with toasted aroma. It was found also in red wines with concentrations between 25 and $140 \mathrm{ng} \mathrm{L}^{-1} 34$. Moreover, benzenemethanethiol was identified in boxwood as well as in red and white wines at concentrations as high as 30-100 fold higher than their perception threshold ${ }^{53}$. These compounds were found in the young Carménère wines from Colchagua and Maipo valleys in concentrations lower than the reported range, but their contribution to the total aroma could not be discarded, because concentrations are greater than their olfactory threshold. 3-mercaptohexyl acetate and 3-mercaptohexan-1-ol have also been identified in Sauvignon Blanc, Riesling, Gewürztraminer, Cabernet Sauvignon and Merlot variety ${ }^{54} .3 \mathrm{MH}$ was reported to have a definitive impact on the fruity aroma of Bordeaux rose wines ${ }^{55}$. Both compounds were also found here with levels over their odor detection threshold (ODT).

Table 2. Minor varietal compounds in Carménère wines.

\begin{tabular}{|l|l|l|}
\hline Compound & Average Conc. $\left(\mathbf{n g ~ L}^{-1}\right)$ & Literature aroma descripton \\
\hline Pyrazines & & \\
\hline IBMP & 3,6 & bell pepper, vegetative, gas \\
\hline & & \\
\hline Thiols & & roasted coffee \\
\hline 2FM & 10,1 & smoky, metallic \\
\hline BM & 14,1 & $\begin{array}{l}\text { box tree, guava aroma, cat } \\
\text { urine, passion fruit }\end{array}$ \\
\hline 4MMP & $\mathrm{nq}$ & $\begin{array}{l}\text { fruity, animal, grape, box tree, } \\
\text { broom, grapefruit }\end{array}$ \\
\hline 3MH & 666,8 & box tree, passion fruit, broom \\
\hline 3MHA & 373,4 & \\
\hline Not quantified compound $(n q)$ &
\end{tabular}

\section{Estimation of high impact olfactory compounds}

An estimation of the potential active odorant compounds of young Carménère wines was carried out using the odour activity value ${ }^{20}$. The $\mathrm{OAV}$ value of any volatile is calculated as the ratio between the measured concentration of a substance in the wine and its odour perception threshold, reported in the literature. This scale allows estimating the relative impact of each compound to the wine aroma. Compounds with $\mathrm{OAV}>1$ are considered to contribute individually to the wine aroma, although it has been suggested that it is also necessary to consider the sensory contribution of those substances with $\mathrm{OAV}>0.2$, because of the additive effect of similar compounds with similar structure or odour ${ }^{56,57}$
Table 3. Estimated OAV average values for odorants compounds identified in Young Carménère wines from Colchagua and Maipo valley.

\begin{tabular}{|c|c|c|c|}
\hline Compound & $\begin{array}{l}\text { Aroma } \\
\text { descriptor }\end{array}$ & $\begin{array}{l}\text { Odour } \\
\text { threshold }\end{array}$ & OAV \\
\hline & & $\left(\mu \mathrm{g} \mathbf{L}^{-1}\right)$ & \\
\hline \multicolumn{4}{|l|}{ Carbonyl compounds } \\
\hline 2,3-butanedione & buttery/caramel & $100^{\mathrm{a}}$ & 7,3 \\
\hline \multicolumn{4}{|l|}{ Alcohols } \\
\hline isoamyl alcohol & $\begin{array}{l}\text { fussel alcohol, } \\
\text { grass, bitter, } \\
\text { harsh }\end{array}$ & $30000^{\mathrm{b}}$ & 1,6 \\
\hline 2-phenylethanol & rose, flowery & $14000^{\mathrm{c}}$ & 1,5 \\
\hline \multicolumn{4}{|l|}{$\begin{array}{l}\text { Lactones and shikimic acid } \\
\text { derivatives }\end{array}$} \\
\hline whiskey lactona $(\mathrm{Z})$ & sweet, coconut & $25^{\mathrm{d}}$ & 7,2 \\
\hline 4-carbethoxy-g-butyrolactone & red fruits, sherry & $400^{\mathrm{e}}$ & 1,2 \\
\hline whiskey lactone (E) & sweet, wood, fruit & $110^{\mathrm{d}}$ & 0,5 \\
\hline vanillin & cake, vanilla & $60^{c}$ & 2,0 \\
\hline \multicolumn{4}{|l|}{ Acids } \\
\hline isobutyric acid & acid, fatty & $230^{\mathrm{f}}$ & 1,4 \\
\hline butyric acid & cheese, rancid & $173^{\mathrm{f}}$ & 1,3 \\
\hline hexanoic acid & fatty, cheese & $420^{\mathrm{f}}$ & 2,6 \\
\hline octanoic acid & fatty & $2200^{\mathrm{e}}$ & 0,8 \\
\hline decanoic acid & rancid, fat & $1000^{\mathrm{f}}$ & 0,4 \\
\hline phenyl acetic acid & honey, flowery & $1000^{\mathrm{f}}$ & 0,2 \\
\hline isovaleric acid & blue cheese & $250^{\mathrm{e}}$ & 4,0 \\
\hline \multicolumn{4}{|l|}{ Esters } \\
\hline ethyl isobutyrate & fruity & $15^{\mathrm{b}}$ & 1,2 \\
\hline ethyl butyrate & kiwi, acid fruit & $20^{\mathrm{c}}$ & 6,0 \\
\hline ethyl isovalerate & fruity, anise & $3^{\mathrm{f}}$ & 2,9 \\
\hline isoamyl acetate & fresh, banana & $30^{c}$ & 30,3 \\
\hline ethyl hexanoate & $\begin{array}{l}\text { fruity, green } \\
\text { apple, anise }\end{array}$ & $14^{\mathrm{g}}$ & 19,1 \\
\hline ethyl octanoate & $\begin{array}{l}\text { fruity, sweet, } \\
\text { soap, anise }\end{array}$ & $5^{\mathrm{g}}$ & 99,9 \\
\hline 2-phenylethyl acetate & roses & $250^{\mathrm{g}}$ & 0,6 \\
\hline ethyl-2-methyl-butyrate** & red fruits & $18^{\mathrm{f}}$ & 0,3 \\
\hline \multicolumn{4}{|l|}{$\begin{array}{l}\text { Sulfur and nitrogen } \\
\text { compounds }\end{array}$} \\
\hline 3-methylthio-1-propanol & $\begin{array}{l}\text { potato, soup, } \\
\text { meat }\end{array}$ & $1000^{\mathrm{g}}$ & 0,4 \\
\hline 2-furanmethanethiol* & roasted coffee & $0,0004^{\mathrm{h}}$ & 25,3 \\
\hline benzenemethanethiol* & smoky, metallic & $0,0003^{\mathrm{i}}$ & 47,4 \\
\hline 3-mercaptohexan-1-ol* & $\begin{array}{l}\text { fruity, grape, box } \\
\text { tree, grapefruit }\end{array}$ & $0,060^{\mathrm{j}}$ & 11,1 \\
\hline 3-mercaptohexyl acetate* & $\begin{array}{l}\text { box tree, passion } \\
\text { fruit, broom }\end{array}$ & $0,004^{i}$ & 93,4 \\
\hline $\begin{array}{l}\text { 2-methoxy-3-isobutyl- } \\
\text { pyrazine* }\end{array}$ & green bell pepper & $0,002^{\mathrm{k}}$ & 1,8 \\
\hline \multicolumn{4}{|l|}{ Terpenes and norisoprenoids } \\
\hline linalool** & orange flowers & $25^{1}$ & 0,3 \\
\hline b-damascenone** & $\begin{array}{l}\text { baked apple, tea, } \\
\text { flower, peach }\end{array}$ & $0,05^{\mathrm{g}}$ & 516,2 \\
\hline \multicolumn{4}{|c|}{$\begin{array}{l}\text { (*) compounds quantified using specific methods; }\left(^{* *}\right) \text { compounds detected } \\
\text { with SPME (PDMS) extraction technique } \\
\text { (Ref) Odor threshold reference: a }{ }^{60} \text { (Santos 2009); } b^{41} \text { (Moreno 2005); } \\
c^{61} \text { (Culleré 2008); d }{ }^{44} \text { (Fernández de Simón 2003); } e^{56} \text { (Rocha 2004); } \\
f^{57} \text { (Vilanova 2009); } g^{35} \text { (Yongsheng Tao 2008); } h^{34} \text { (Tominaga 2006); } \\
\text { (Tominaga 2003); } j^{54} \text { (Tominaga 2006); } k^{16} \text { (Belancic 2007) and l }{ }^{20} \\
\text { (Zalacain 2007). }\end{array}$} \\
\hline
\end{tabular}


Table 3 contains the compounds present in the Carménère wines with significant OAV values. b-damascenone could be considered as the most powerful odorant $(\mathrm{OAV}=516)$ in agreement with the information reported for other red wines ${ }^{51}$ and some white wines from Galicia ${ }^{57}$. Ethyl octanoate and 3-mercaptohexyl acetate showed also very high values, around 100 $\mathrm{OAV}$, in average. Several other compounds also exhibited OAV $>1$ like the esters ethyl hexanoate, ethyl butyrate, ethyl isovalerate and isoamyl acetate. Esters contribute favourably to wine aroma with fruity characteristics. Among the varietal compounds the thiols benzenemethanethiol (smoky), 2-furanmethanethiol (toasty) and 3-mercaptohexan-1-ol (grapefruit, tropical fruitds) also contribute to the Carménère aroma. Fatty acids: C4-C6 (sour, rancid, fatty, cheesy notes); the alcohols: 2-phenylethanol (roses scent) and isoamyl alcohol (fusel alcohol); diacetyl (buttery/caramel); and the lactones: whisky lactone (woody, coconut) and the 4-carbethoxy-g-butyrolactone (red berries, sherry nuances) were in concentrations greater than their ODT. However, the contribution to the total aroma of substances with near-unity OAVs cannot be ignored, because they could enhance some existing notes by synergy with other compounds.

\section{CONCLUSIONS}

The Carmenere wines studied here belong to two premium wineries, Casa Silva and Perez Cruz, located at two different Chilean viticultural regions (Colchagua and Maipo valleys). Liquid-liquid extraction and headspace solid phase microextraction methods showed to be complementary in the characterization of the aroma profile of Carménère wines. Except for some differences that could be associated with the terroir or prefermentation and vinification practices, the two Carménère wines had similar features: the varietal compounds 2-isobutyl-3-methoxypyrazine, benzenemethanethiol, 2-furanmethanethiol, 3-mercaptohexan-1-ol, 3-mercaptohexyl acetate and the norisoprenoid b-damascenone constitute potential high impact odorants of the aroma of Carmenerre wines. Isobutylmethoxypyrazine and and several thiols, present in trace levels concentration, were also found to be significant contributors. On the other hand, fermentative compounds, such as esters (isoamyl acetate, ethyl octanoate and ethyl hexanoate), alcohols (isoamyl alcohol, 2-phenyl ethanol) and fatty acids (butyrics, hexanoic and octanoic acids), as well as wood-derived volatiles, like lactones (whiskey and 4-carbetoxy-g-butyro lactone), could also be involved in the aroma of these wines. Nevertheless, although the contribution to overall aroma of varietal substances, such as 3-oxo-a-ionol, ethyl hydroxybutanoate and the terpenes linalool, citronellol and nerolidol could not be demonstrated, their contribution to the whole aroma, alone or in combination with other compounds could not be totally discarded.

\section{ACKNOWLEDGEMENTS}

The author wants to thank CONICYT-FONDECYT postdoctoral project $\mathrm{N}^{\circ} 3080050$ for the financial support of this work, as well as the winemakers Jose Ignacio Maturana and German Lyon and the Casa Silva and Pérez Cruz wineries for their interest in this work and kindly selecting and providing the wines employed in this study; and the staff of the Centro de Aromas (DICTUC, Pontificia Universidad Catolica de Chile) for their collaboration.

\section{REFERENCES}

1.- V. Ferreira, P. Fernández, J.F. Cacho, Lebensm.-Wiss. u.-Technol. 29, 251, (1996).

2.- $\quad$ V. Ferreira, N. Ortín, J.F. Cacho, J. Chromatogr. A, 1143, 190, (2007).

3.- M.E.O. Mamede, G.M. Pastore, Food Chem. 96, 586, (2006).

4.- $\quad$ K.A. Bindon, P.R. Dry, B.R. Loveys, J. Agric. Food Chem. 55, 4493, (2007).

5.- $\quad$ I. Sabon, G. de Revel, Y. Kotseridis, A. Bertrand, J. Agric. Food Chem. 50, 6341, (2002).

6.- J.M. Oliveira, M. Faria, F. Sá, F. Barros, I.M. Araújo, Anal. Chim. Acta, 563, 300, (2006).

7.- M.C. Díaz-Maroto, R.M. Schneider, R. Baumes, J. Agric. Food Chem 53, 3503, (2005).

8.- M. Gil, J.M. Cabellos, T. Arroyo, M. Prodanov, Anal. Chim. Acta, 563, 145, (2006).

9.- C. Augustin, S. Bonhomme, M.L. Murat, I. Masneuf, in www.infowine. com, Rev. Internet de Vitic. y Enol. 8, 1, (2006).

10.- E. Sánchez, M.S. Pérez, M.C. Díaz, M.A. González, M.D. Cabezudo, Food Chem. 95, 279, (2006).
11.- J.S. Câmara, M.A. Alves, J.C. Marques, Food Chem. 101, 475, (2007).

12.- T.E. Siebert, C. Wood, G.M. Elsey, A.P. Pollnitz, J. Agric. Food Chem. 56, 3745, (2008).

13.- V. Ferreira, I. Jarauta, R. López, J. Cacho, J. of Chromatogr. A, 1010, 95, (2003).

14.- E. Campo, V. Ferreira, A. Escudero, J. Cacho, J. Agric. Food Chem. 53 5682, (2005).

15.- L.D. Falcão, G. de Revel, J.P. Rosier, M.T. Bordignon, Food Chem. 107, 497, (2008).

16.- A. Belancic, E. Agosin, Am. J. Enol. Vitic. 58, 462, (2007).

17.- L. Ortega, R. López, J. Cacho, V. Ferreira, J. Chromatogr. A, 931, 31, (2001).

18.- Z. Piñeiro, M. Palma, C.G. Barroso, Anal. Chim. Acta, 513, 209, (2004).

19.- M.J. Gómez, J.F. Cacho, V. Ferreira, I.M. Vicario, F.J. Heredia, Food Chem. 100, 1464, (2007).

20.- A. Zalacain, J. Marín, G.L. Alonso, M.R. Salinas, Talanta, 71, 1610, (2007).

21.- A. Tredoux, A. de Villiers, P. Májek, F. Lynen, A. Crouch, P. Sandra, J. Agric. Food Chem. 56, 4286, (2008).

22.- Y. Fang, M. Qian, Flavour Fragr. J. 20, 22, (2005).

23.- J. Wenguang, F. Wenlai, X. Yan, Z. Guangáo, L. Jiming, Y. Ying, Chin. J. Chromatogr. 25, 881, (2007).

24.- L. Rosillo, M.R. Salinas, J. Garijo, G.L. Alonso, J. Chromatogr. A, 847, 155, (1999).

25.- A. Escudero, E. Campo, L. Fariña, J. Cacho, V. Ferreira, J. Agric. Food Chem. 55, 4501, (2007).

26.- R.R. Nelson, T.E. Acree, R.M. Butts, J. Agric. Food Chem. 26, 1188 , (1978).

27.- M. Ortega, M.L. González, S. Beltrán, Anal. Chim. Acta, 458, 85, (2002).

28.- D. Hernanz, V. Gallo, Á.F. Recamales, A.J. Meléndez, F.J. Heredia, Talanta, 76, 929, (2008).

29.- E. Sánchez, M.C. Díaz, M.S. Pérez, Talanta, 66, 1152, (2005).

30.- J. Bosch, M. Riu, J.M. Guadayol, J. Caixach, E.S. Buxaderas, Food Chem. 105, 428, (2007).

31.- V. Canuti, M. Conversano, M. Li Calzi, H. Heymann, M.A. Matthews, S.E. Ebeler, J. Chromatogr. A, 1216, 3012, (2009).

32.- C.M. Kalua, P.K. Boss, J. Agric. Food Chem. 57, 3818, (2009).

33.- G. Casaubon, A. Belancic, E. Agosin, Rev. Vendimia, Dic., 37, (2006).

34.- T. Tominaga, D. Dubourdieu, J. Agric. Food Chem. 54, 29, (2006).

35.- Y. Tao, H. Li, H. Wang, L. Zhang, J. Food Comp. Anal. 21, 689, (2008).

36.- M. Ugliano, L. Moio, J. Agric. Food Chem. 53, 10134, (2005).

37.- E. Boido, A. Lloret, K. Medina, L. Fariña, F. Carrau, G. Versini, E. Dellacassa, J. Agric. Food Chem. 51, 5408, (2003).

38.- R.J. Elias, V.F. Laurie, S.E. Ebeler, J.W. Wong, A.L. Waterhouse, Anal. Chim. Acta, 62, 6104, (2008).

39.- F.S.S. Rogerson, H. Castro, N. Fortunato, Z. Azevedo, A. Macedo, V.A.P. de Freitas, J. Agric. Food Chem. 49, 263, (2001).

40.- E.J. Bartowsky, P.A. Henschke, Int. J. Food Microbiol. 96, 235, (2004).

41.- J.A. Moreno, L. Zea, L. Moyano, M. Medina, Food Control, 16, 333, (2005).

42.- M. Mestres, O. Busto, J. Guasch, J. Chromatogr. A, 881, 569, (2000).

43.- M. Mestres, M.P. Martí, O. Busto, J. Guasch, J. Chromatogr. A, 881, 583, (2000).

44.- B. Fernández, E. Cadahía, J. Jalocha, J. Agric. Food Chem. 51, 7671, (2003).

45.- J.J. Rodríguez, M. Ortega, S. Pérez, C. González, M.L. González, J. Agric. Food Chem. 56, 5102, (2008).

46.- A. Genovese, A. Gambuti, P. Piombino, L. Moio, Food Chem. 103, 1228, (2007).

47.- J.J. Mateo, M. Jiménez, J. Chromatogr. A, 881, 557, (2000).

48.- M.M. Mendes, Arch. Biochem. Bioph. 483, 236, (2009).

49.- A. Belancic, E. Agosin, Inf. Téc. Rev. Vendimia, año 9 (55), 52, (2007).

50.- A. Belancic, E. Agosin, unpublished report, (2010).

51.- R. López, E. Ezpeleta, I. Sanchez, J. Cacho, V. Ferreira, Food Chem. 88, 95, (2004)

52.- B. Pineau, J.C. Barbe, C. Van Leeuwen, D. Dubourdieu, J. Agric. Food Chem. 55, 4103, (2007).

53.- T. Tominaga, G. Guimbertau, D. Dubourdieu, J. Agric. Food Chem. 51, 1373, (2003)

54.- T. Tominaga, Y. Niclass, E. Freärot, D. Dubourdieu, J. Agric. Food Chem. 54, 7251, (2006).

55.- M.L. Murat, T. Tominaga, D. Dubourdieu, J. Agric. Food Chem. 49, $5412,(2001)$ 
56.- S.M. Rocha, F. Rodrigues, P. Coutinho, I. Delgadillo, M.A. Coimbra, Anal. Chim. Acta, 513, 257, (2004).

57.- M. Vilanova, Z. Genisheva, A. Masa, J.M. Oliveira, Microchem. J. 95 (2), $240,(2010)$

58.- V. Ferreira, A. Escudero, E. Campo, J. Cacho in South Australian Wine Industry Thecnical Conference, Thirteenth Australian Wine Industry Technical Conference Inc Proceedings. The chemical foundations of wine aroma - a role game aiming at wine quality, personality and varietal expression, R.J. Blair, P.J. Williams \& I.S. Pretorious eds., Adelaide, 2007, p. 142.
59.- B. Pineau, J.C. Barbe, C. Van Leeuwen, D. Dubourdieu, J. Agric. Food Chem. 57, 3702, (2009).

60.- J.P. Santos, J. Lozano, M. Aleixandre, T. Arroyo, J.M. Cabellos, M. Gil, M.C. Horrillo, Talanta, 80 (5), 1899, (2010).

61.- L. Culleré, A. Escudero, J.P. Pérez, J. Cacho, V. Ferreira, J. Food Comp. Anal. 21, 708, (2008) 